\title{
Anodization Parameters Influencing the Growth of Titania Nanotubes and Their Photoelectrochemical Response
}

\author{
Ying-Chin Lim, ${ }^{1}$ Zulkarnain Zainal, ${ }^{1,2}$ Wee-Tee Tan, ${ }^{3}$ and Mohd Zobir Hussein ${ }^{1,2}$ \\ ${ }^{1}$ Centre of Excellence for Catalysis Science and Technology and Department of Chemistry, Faculty of Science, Universiti Putra Malaysia, \\ Selangor Darul Ehsan, 43400 Serdang, Malaysia \\ ${ }^{2}$ Advanced Materials and Nanotechnology Laboratory, Institute of Advanced Technology (ITMA), Universiti Putra Malaysia, \\ Selangor Darul Ehsan, 43400 Serdang, Malaysia \\ ${ }^{3}$ Department of Chemistry, Faculty of Science, Universiti Putra Malaysia, Selangor Darul Ehsan, 43400 Serdang, Malaysia
}

Correspondence should be addressed to Zulkarnain Zainal, zulkar@science.upm.edu.my

Received 14 September 2011; Revised 19 November 2011; Accepted 19 November 2011

Academic Editor: Jiaguo Yu

Copyright (c) 2012 Ying-Chin Lim et al. This is an open access article distributed under the Creative Commons Attribution License, which permits unrestricted use, distribution, and reproduction in any medium, provided the original work is properly cited.

$\mathrm{TiO}_{2}$ nanotubes (TNTs) were fabricated by electrochemical oxidation of Ti foil in a standard two-electrode cell-containing $\mathrm{NH}_{4} \mathrm{~F}$. The effects of bath temperature, voltage ramp prior to constant voltage held during anodization and present of complexing agent on the crystalline phase, nanotube growth, and dimensional change of TNT were investigated using XRD and FESEM. The results show that tube length decreases with bath temperature attributed to faster chemical dissolution rate at high temperature. However, nanotubes growth rate was enhanced by $\sim 260 \%$ with the addition of EDTA as the complexing agent. Meanwhile, the nanotubes diameter was found to be proportionally dependent on bath temperature but independent of the voltage ramp and addition of EDTA. Photoelectrochemical response under illumination was enhanced by using the calcined TNT and is strongly affected by its dimensional changes. Thus, desired properties of TNT can be obtained by tuning the electrochemical condition for a wide-range application.

\section{Introduction}

Over the past decades, titania has gained much attention compared to other oxide semiconductor due to its remarkable properties including strong oxidizing power, nontoxicity, chemical and biological inertness, and long-term photostability. Thus, it has found enormous application in photocatalysis [1-9], photoelectrochemical water splitting $[10,11]$, self-cleaning application [12], sensing [13, 14], and photovoltaic cells $[15,16]$. In addition, high level biocompatibility nature of titania facilitates its application in biomedical field where $\mathrm{TiO}_{2}$ layers on $\mathrm{Ti}$ or $\mathrm{Ti}$ alloys are in direct contact with biological tissue in dental implants and orthopedic applications $[17,18]$. Compared with conventional $\mathrm{TiO}_{2}$ nanoparticles, $\mathrm{TiO}_{2}$ nanotubes (TNTs) offer some peculiar advantages such as high specific surface area resulting from the hollow channel structure, high mechanical stability, and unique nanoarchitecture with fewer interfacial grain boundaries, which promote charge transport and enhanced electron-hole separation [16].
Thus, considerable studies have been focused on fabricating TNT including sol-gel [19], hydrothermal processes $[20,21]$, template-assisted synthesis [22], seeded growth [23], and electrochemical anodization [24]. Among the synthetic methodology, electrochemical anodization of $\mathrm{Ti}$ in electrolytes containing fluoride provides a relatively simple and effective way of synthesizing nanotubular or porous structures. The synthesized nanotubes are highly ordered, well-defined with high aspect ratios, and are vertically oriented to the substrate. Most importantly, the dimensions of nanotubes could be controlled precisely and modified easily by choosing the suitable electrochemical conditions. Zwilling et al. [25] in 1999 were the first to report on successful anodization of Ti and its alloy (Ti-6Al-4V) which was carried out in chromic acid with and without the addition of hydrofluoric acid. In 2001, Grimes and coworkers [26] have successfully synthesized well-aligned and highly ordered TNT through potentiostatic anodization of Ti in aqueous electrolyte containing hydrofluoric acid. Following this work, TNT with various diameters $(22-600 \mathrm{~nm})$, tube 
lengths $(0.2-1000 \mu \mathrm{m})$, and wall thicknesses $(7-34 \mathrm{~nm})$ has been obtained by controlling the electrochemical conditions. Nanoarchitecturing processes of this material and its unique properties could be obtained from a variety of reports in the literature [27-33], thus making it of considerable interest in scientific community and practical importance.

To date, the mechanistic model for nanotubes formation is believed to be the formation of pits by $\mathrm{F}^{-}$which later develops into pores and transform into cylindrical nanotubular structures. Also, the nanotubes growth inward the Ti occurs at the bottom of nanotubes (tube tip) followed by oxidation at that region. Both the oxidation and dissolution rate of the tube tip are affected by several anodization conditions including bath temperature, electric field across the oxide layer, and the amount of $\mathrm{F}^{-}$present. However, few studies have been carried out to study the effect of this important anodization conditions (e.g., bath temperature) on the morphology, nanotube growth, and photoelectrochemical properties of TNT $[34,35]$.

In this work, we accomplished the systematic study of the anodization conditions by expanding our investigation on the effect of bath temperature, voltage sweeping rate and addition of complexing agent on the formation and growth of TNT using previously optimized conditions [36]. Even though Banerjee et al. [37] has investigated the use of complexing agent on the growth of TNT, however, organic electrolyte with $\mathrm{pH} \approx 6.4$ was being used in their work. To the best of our knowledge, this is the first report on the effect of complexing agent in aqueous electrolyte on the dimensional change of the TNT. As the photo-induced processes are strongly dependent on the morphology, microstructures, and anodization conditions, study on the photoelectrochemical properties of TNT synthesized under different experimental conditions was investigated and discussed.

\section{Experimental}

2.1. Preparation of $\mathrm{TiO}_{2}$ Nanotubes. Sheets of $\mathrm{Ti}$ foil $(0.127 \mathrm{~mm}, 99.7 \%$, Sigma Aldrich) were first cut into small rectangular size of $10 \mathrm{~mm} \times 25 \mathrm{~mm}$. Prior to anodization, they were degreased by sonicating in acetone, isopropanol, and deionized (DI) water, followed by chemically etched in $6 \mathrm{M} \mathrm{HNO}_{3}$ for 10 minutes. Then, they were rinsed with excess DI water and dried in air. Electrochemical anodization of Ti was carried out in a homemade designed two-electrode cell with clean $\mathrm{Ti}$ foil as the working electrode and a high density graphite electrode as the counter electrode. All anodization experiments were conducted at room temperature $\left(\sim 27^{\circ} \mathrm{C}\right.$ except when studying the effect of bath temperature) in $0.15 \mathrm{M} \mathrm{NH}_{4} \mathrm{~F}$ adjusted to $\mathrm{pH} 4$ using $\mathrm{H}_{2} \mathrm{SO}_{4}$. Anodization was carried out by applying a constant voltage with no ramp (except when studying the effect of voltage ramp) using a DC power supply (Consort Mini, Cleaver Scientific Ltd). To investigate the effect of EDTA in the formation of TNT, $0.2 \mathrm{M}\left(\mathrm{Na}_{2}\left[\mathrm{H}_{2} \mathrm{EDTA}\right]\right)$ and $\mathrm{NH}_{4} \mathrm{~F}$ were mixed together at $\mathrm{pH}$ 4.5. The resultant TNT is hereinafter designated as TNT/EDTA. To facilitate comparison, another TNT sample was also synthesized without the addition of
EDTA under similar experimental condition ( $\mathrm{pH}$ 4.5). From our previous work [34], it is known that anodization of less than $10 \mathrm{~V}$ resulted in ring-like structure while highlyordered and well-defined nanotubes were obtained at a voltage of $10 \mathrm{~V}$ and above. Employing higher voltage yielded a nanoporous at $30 \mathrm{~V}$ and nodule-like structure at $40 \mathrm{~V}$. Hence, in this study, applied voltage was limited to $20 \mathrm{~V}$ to synthesize all the TNT films. The anodized samples were immediately rinsed with deionized water and subsequently dried in air. Calcination of films was carried out in a Thermolyne 21100 furnace at $500^{\circ} \mathrm{C}$ in open air atmosphere with a heating rate of $2^{\circ} \mathrm{C} / \mathrm{min}$ for $2 \mathrm{~h}$.

2.2. Characterization of As-Anodized and Calcined $\mathrm{TiO}_{2}$ Nanotubes. The crystallinity of the as-anodized and calcined TNT films was determined by X-ray diffraction (XRD@Shimadzu D6000) using a diffractometer with $\mathrm{Cu}$ $\mathrm{K}_{\alpha}$ radiation $(\lambda=1.5406 \AA)$. The surface morphology of the films was acquired by a field-emission scanning electron microscope, FESEM (Zeiss SUPRA 40 VP, Germany) operating at electron beam voltage of $5 \mathrm{kV}$. Quantitative measurements of the geometrical features of TNT were done using image analysis software; Image J. About 100 measurements of tube diameter and wall thickness were taken per sample from three different locations to ensure the measurements were representative. In order to obtain the thickness of the nanotube layer, direct cross-sectional micrographs were taken from mechanically bent samples. At least five measurements of the cross section were taken from different areas on each sample to ensure the measurements reflected the actual tube length. Photoelectrochemical current response measurements were performed in a conventional three-electrode cell equipped with a flat quartz window. It consisted of a synthesized TNT working electrode, a platinum wire counter electrode, and an $\mathrm{Ag} / \mathrm{AgCl}$ reference electrode. The photocurrent was measured with a scanning potentiostat ( $\mu$-III AUTOLAB) under chopped irradiation from $120 \mathrm{~V} 300 \mathrm{~W}$ halogen lamp during a potential sweep from +2.0 to $-0.2 \mathrm{~V}$ with a sweep rate of $20 \mathrm{mV} / \mathrm{s}$. The TNT films were irradiated from the front side through the quartz window in a $10 \mathrm{ppm}$ methyl orange solution with $0.1 \mathrm{M} \mathrm{KCl}$ as the supporting electrolyte.

\section{Results and Discussion}

3.1. Effect of Bath Temperature. Figure 1 depicts the XRD patterns of as-anodized (at $35^{\circ} \mathrm{C}$ ) and calcined TNT. It is obvious that TNT synthesized at $35^{\circ} \mathrm{C}$ (Figure $1(\mathrm{a})$ ) exhibits amorphous structure as only diffraction peaks of Ti substrate (JCPDS no. 44-1294) are visible, which is similar to TNT fabricated at room temperature $\left(\sim 27^{\circ} \mathrm{C}\right)$ [36]. Although Xiao et al. observed formation of crystalline TNT in dimethyl sulfoxide at electrolyte temperature of 50$60^{\circ} \mathrm{C}$ [38], however, bath temperature higher than $35^{\circ} \mathrm{C}$ is not being used in our study as this lead to the formation of different surface morphology other than nanotubes as will be discussed later. Nevertheless, TNT crystallizes to form a mixture of anatase (101) at $25.4^{\circ}$ (JCPDS no. 21-1272) 


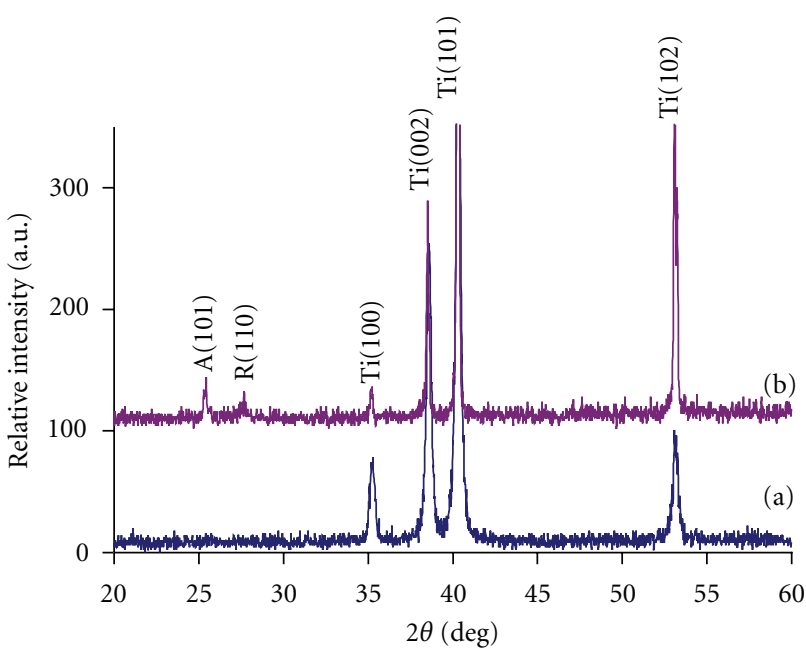

FIGURE 1: XRD patterns of (a) as-anodized TNT synthesized at $35^{\circ} \mathrm{C}$ and (b) calcined TNT. A, R, and Ti represent anatase, rutile, and titanium, respectively.

and rutile (110) (JCPDS no. 21-1276) phase at $27.6^{\circ}$ after calcination at $500^{\circ} \mathrm{C}$ as shown in Figure $1(\mathrm{~b})$.

TNT was synthesized at $20 \mathrm{~V}$ in five different electrolyte bath temperatures: $10,18,27,35$, and $40^{\circ} \mathrm{C}$. Figure 2 shows the FESEM micrographs of the top morphology of TNT fabricated in different bath temperatures. It can be clearly seen that TNT fabricated at low bath temperature was covered with lots of surface debris whereas clean TNT could be obtained when much higher anodization temperature was used $\left(18^{\circ} \mathrm{C}\right.$ and above) as shown in Figures 2(a)2(c). In addition, tube length changes by a factor of two, corresponding to a decrease in length with increasing anodization temperature from $430 \pm 16 \mathrm{~nm}$ at $10^{\circ} \mathrm{C}$ to $240 \pm$ $13 \mathrm{~nm}$ at $35^{\circ} \mathrm{C}$. For tube wall thickness, only slight decrease from $21 \pm 3 \mathrm{~nm}$ to $15 \pm 3 \mathrm{~nm}$ could be observed.

For electrochemical oxidation of Ti in fluorinated electrolyte, it is well known that there are three processes, namely, field-assisted oxidation of $\mathrm{Ti}$, field-assisted dissolution of $\mathrm{Ti}$ metal ions, and chemical etching of $\mathrm{Ti}$ and $\mathrm{TiO}_{2}$ by fluoride ions that control the formation of TNT. As both chemical etching process and solubility of product ions are greatly affected by temperature change, with etching rates typically being exponential functions of the temperature. Therefore, at lower anodization temperature, thicker wall and longer tube obtained could be ascribed to weaker chemical dissolution at the pore bottom as well as slower oxide etching rate by fluoride ions at the tube top [39]. On the contrary, chemical dissolution by $\mathrm{F}^{-}$and dissolution of oxide layer occurs at a faster rate at higher temperature. Chemical dissolution at the tube bottom will reduce the thickness of the oxide layer, and hence field-assisted dissolution will reoccur at the tube bottom. By this process, pores will penetrate the Ti substrate resulting in longer nanotube. However, shorter tube observed at high temperature in this study might be due to that chemical dissolution rate at the tube top occurs faster than that at the tube bottom. Nevertheless, it is worth mentioning that tube diameter increases with increasing anodization temperature being $58 \pm 7 \mathrm{~nm}$ at $10^{\circ} \mathrm{C}$ and 81 $\pm 11 \mathrm{~nm}$ at $35^{\circ} \mathrm{C}$. This observation, however, is in contrast with the finding reported by Mor et al. [39] who found no discernible change in tube diameter fabricated at different electrolyte temperatures. As reported elsewhere, change in tube diameter is generally influenced by applied voltage with larger tube diameter associated with the use of higher applied voltage $[40,41]$.

Larger tube diameter observed at high anodization temperature may be ascribed to increase in horizontal dissolution as the earlier formed parts of the tube wall (tube mouth) at the top are subjected to longer exposure in fluoride etching environment and thus decelerating dissolution in vertical direction [42]. As a result, tube growth at the tube bottom will be relatively slower. In contrast, the tube mouth will experience relatively faster dissolution leading to larger tube diameter.

Nanotubular structure completely disappeared (Figure 2(d)) when anodization of $\mathrm{Ti}$ is carried out at $40^{\circ} \mathrm{C}$, suggesting a temperature limit above which nanotubular structure will diminish. It is known that soon after oxide layer is formed, dissolution occurs from many directions and, with increasing anodization temperature, velocity of $\mathrm{F}^{-}$drift also increases. This led to faster chemical dissolution of oxide layer at multiple directions before formation of nanotubular structure. Moreover, it is believed that magnetic agitation during anodization enhanced the severity of chemical dissolution which in return results in the formation of nodule-like structure observed at $40^{\circ} \mathrm{C}$.

3.2. Effect of Voltage Ramp prior to Constant Potential. It was also noticed that the length of TNT could be controlled by voltage ramp prior to constant voltage at $20 \mathrm{~V}$ during anodization. By employing a voltage ramp, a desired $\mathrm{pH}$ gradient could be established between the tube bottom and the tube mouth. Thus this will create a preference environment conducive for the growth of longer tube [43].

Figures 3(a) and 3(b) show the polarization curves for voltage ramp rate between $10 \mathrm{mV} / \mathrm{s}$ and $350 \mathrm{mV} / \mathrm{s}$ and current transients at $20 \mathrm{~V}$ once the voltage ramp has ended, respectively. It is apparent from Figure 3(a) that the current density increases at the beginning of anodization, followed by a sudden drop indicating the formation of thin barrier oxide layer.

However, it is observed that the exact position for the current density rise strongly depends on the voltage ramp rate (see corresponding solid arrow in Figure 3(a)), consistent with different electric fields driving ion transport during voltage ramping [35]. Current fluctuations during voltage ramping could be observed after the initial sudden drop is ascribed to the field-assisted oxidation which increased the resistance of the oxide layer and field-assisted dissolution promoted by $\mathrm{F}^{-}$(pore formation).

Once the voltage ramp was terminated, the current becomes relatively constant as shown in Figure 3(b), indicating an equilibrium between pore growth rate at the bottom of the pores and chemical etching rate of the oxide film at the oxide/electrolyte interface is achieved leading to tube 


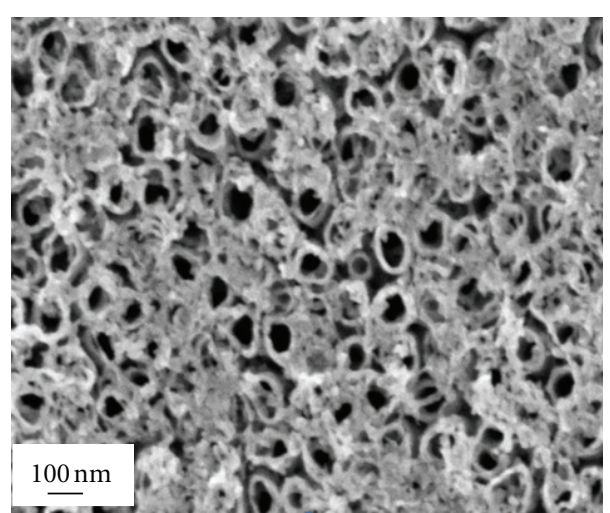

(a)

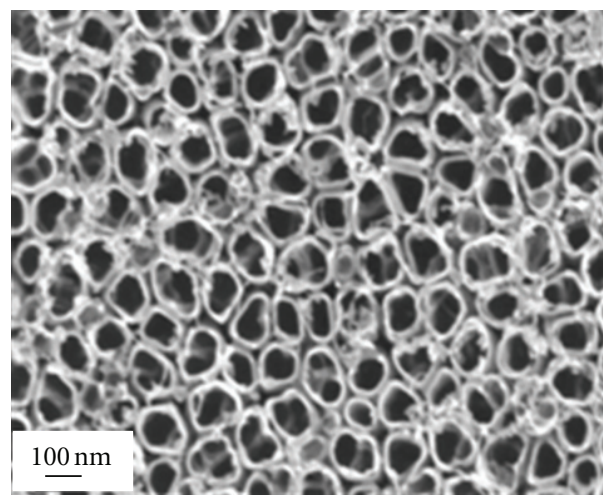

(c)

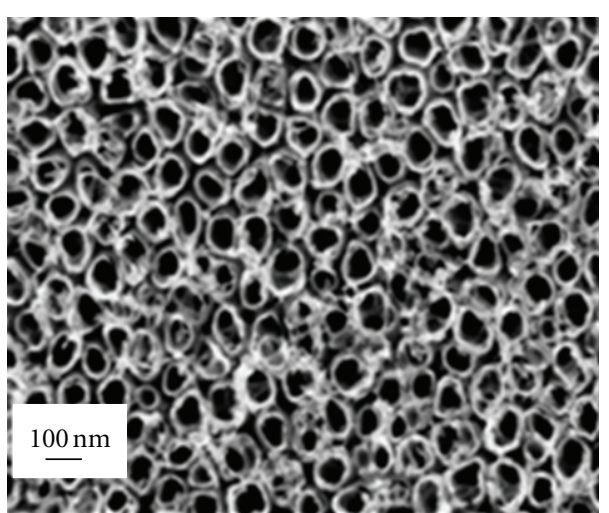

(b)

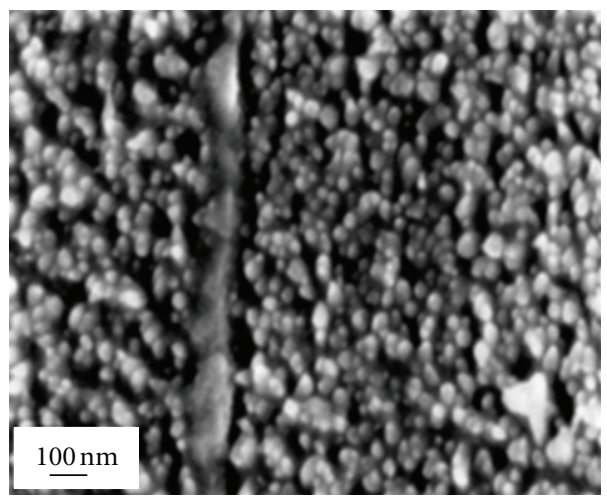

(d)

Figure 2: FESEM images of TNT synthesized at (a) $10^{\circ} \mathrm{C}$, (b) $18^{\circ} \mathrm{C}$, (c) $35^{\circ} \mathrm{C}$, and (d) $40^{\circ} \mathrm{C}$ for $1 \mathrm{~h}$.

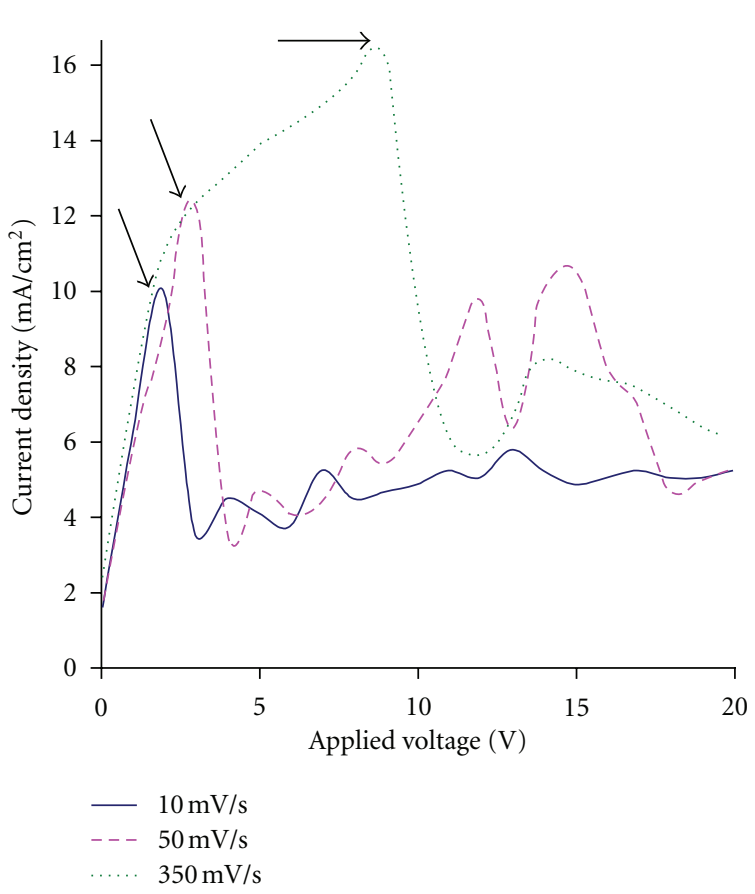

(a)

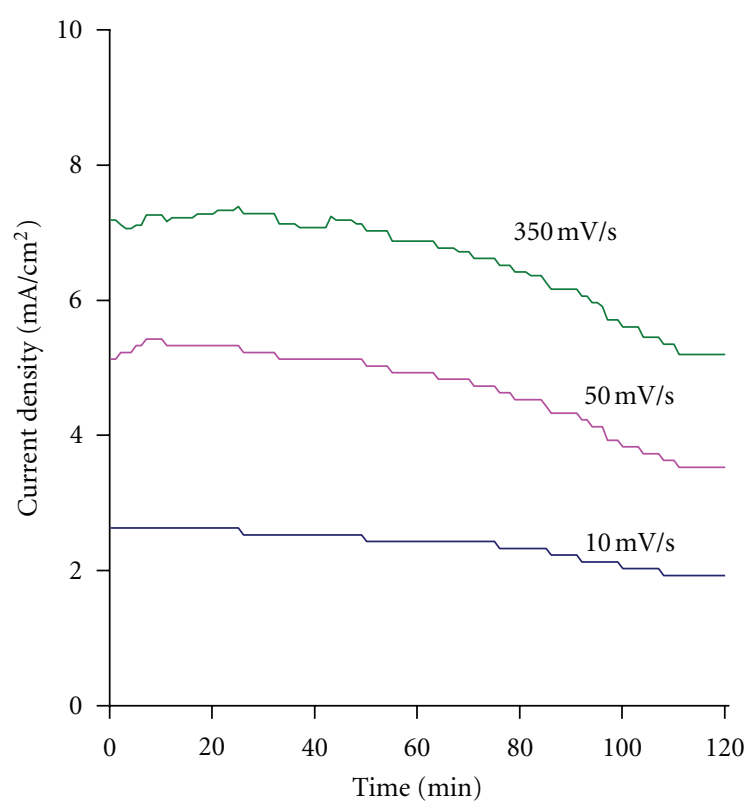

(b)

Figure 3: (a) Polarization curves at different voltage ramps prior to constant voltage at $20 \mathrm{~V}$ and (b) current transients at $20 \mathrm{~V}$ after the voltage ramp has completed. 


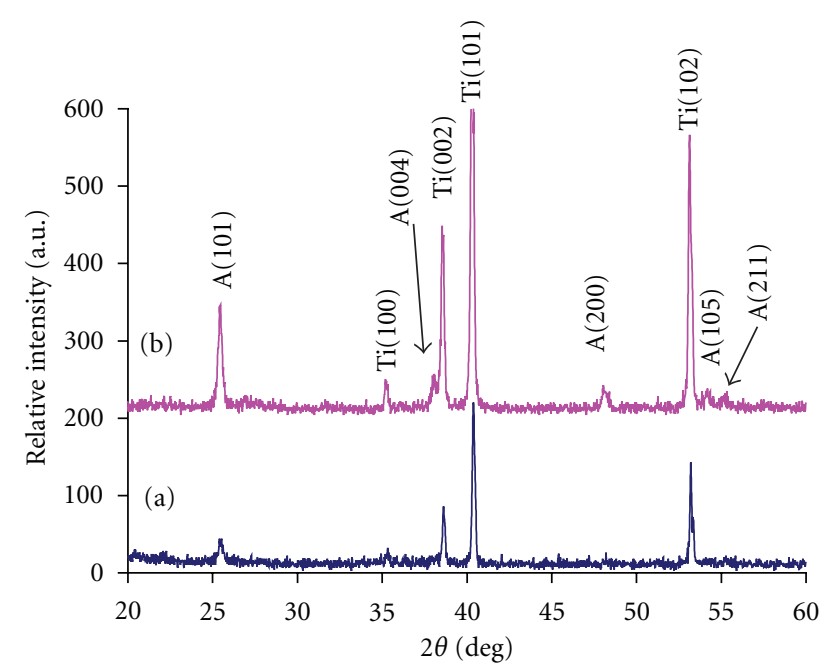

FIgURE 4: XRD patterns of (a) TNT and (b) TNT/EDTA calcined at $500^{\circ} \mathrm{C}$. A and Ti represent anatase and titanium, respectively.

TABle 1: Dimensional data of TNT produced at different voltage ramps prior to constant voltage of $20 \mathrm{~V}$.

\begin{tabular}{lccc}
\hline $\begin{array}{l}\text { Voltage ramp } \\
(\mathrm{mV} / \mathrm{s})\end{array}$ & $\begin{array}{c}\text { Tube diameter } \\
(\mathrm{nm})\end{array}$ & $\begin{array}{c}\text { Wall thickness } \\
(\mathrm{nm})\end{array}$ & $\begin{array}{c}\text { Tube length } \\
(\mathrm{nm})\end{array}$ \\
\hline 10 & $67 \pm 9$ & $15 \pm 3$ & $444 \pm 11$ \\
50 & $70 \pm 8$ & $17 \pm 3$ & $607 \pm 18$ \\
350 & $70 \pm 6$ & $16 \pm 3$ & $388 \pm 9$ \\
No ramp & $75 \pm 9$ & $17 \pm 4$ & $393 \pm 17$ \\
\hline
\end{tabular}

formation [44]. TNT produced without applying voltage ramp prior to constant voltage has a length of about $390 \mathrm{~nm}$ which is similar to that synthesized using voltage ramp of $350 \mathrm{mV} / \mathrm{s}$ as shown in Table 1 . No significant structural different was observed for TNT formed with a difference voltage ramp.

Nevertheless, it is noted that lowering the ramp to $50 \mathrm{mV} / \mathrm{s}$ did increase the tube length to about $600 \mathrm{~nm}$, suggesting that pore formation occurs while the oxide layer is relatively thin. Further decreasing the ramp to $10 \mathrm{mV} / \mathrm{s}$ does not increase in the layer thickness. Therefore, employing $50 \mathrm{mV} / \mathrm{s}$ prior constant voltage could be regarded as the optimized voltage ramp as thickest oxide layers are obtained. It is also observed that the tube diameter is independent of voltage ramp, which is mainly affected by anodization voltage [34].

3.3. Effect of Addition of Complexing Agent. Figure 4 shows the XRD pattern of TNT and TNT/EDTA anodized at $20 \mathrm{~V}$ for $1 \mathrm{~h}$ in $\mathrm{pH} 4.5$ electrolyte. Even though no significant difference in crystal phase was observed for both samples, however, relative intensity of anatase peak at $25.4^{\circ}$ (101) increases for TNT/EDTA sample. In addition, TNT/EDTA sample also possessed additional anatase peaks at $38.1^{\circ}$ (004), $48.1^{\circ}(200), 54.0^{\circ}(105)$, and $55.1^{\circ}$ (211), respectively. Therefore, it is reasonable to infer that the tube length (thickness of oxide layer) of the TNT/EDTA sample had increased compared to TNT sample.

Figures 5(a) and 5(b) show the representative FESEM images of TNT and TNT/EDTA samples and it is obvious that no morphology changes for both samples. From the inset in Figure 5, highly ordered nanotubes with open mouth were formed, and the average inner diameter was measured to be $63 \pm 8 \mathrm{~nm}$ and the outer diameter was of $92 \pm 11 \mathrm{~nm}$, with a wall thickness of $15 \pm 4 \mathrm{~nm}$. However, the crosssectional view of TNT/EDTA (Figure 5(b)) clearly reveals that addition of EDTA has played a very vital role in increasing the tube length by 2.6 times from $300 \pm 19$ to $770 \pm 58 \mathrm{~nm}$ within $1 \mathrm{~h}$ of anodization with a growth rate of approximately $13 \mathrm{~nm} / \mathrm{min}$.

As shown in Figure 6, an initial current drop during anodization for both TNT and TNT/EDTA samples was observed due to the formation of an oxide layer. However, two different current behaviors could be observed depending on the presence of complexing agent. In the absence of EDTA, a gradual increase in current density is observed ascribed to the thinning of the oxide layer (promoted by $\mathrm{F}^{-}$) until it reaches a steady state. At this stage, nanotube formation takes place and no thickness change exists in the barrier oxide layer. With the presence of EDTA, current density decreases smoothly after the initial current decay without a local minimum.

EDTA is widely recognized as an efficient chelating agent. In aqueous acidic electrolyte, it is believed that $\mathrm{Ti}$ metal oxidizes to form a thin oxide layer on the Ti metal at the solid-liquid interface under applied voltage according to.

$$
\mathrm{Ti}+2 \mathrm{H}_{2} \mathrm{O} \longrightarrow \mathrm{TiO}_{2}+4 \mathrm{H}^{+}+4 \mathrm{e}^{-} .
$$

Even though $\mathrm{TiO}_{2}$ is thermodynamically stable in both acidic and alkaline medium, however, with the presence of $\mathrm{F}^{-}$ and $\left[\mathrm{H}_{2} \mathrm{EDTA}\right]^{2-}$, substantial chemical dissolution occurs according to the following [37, 44, 45]:

$$
\begin{gathered}
\mathrm{TiO}_{2}+6 \mathrm{~F}^{-}+4 \mathrm{H}^{+} \longrightarrow\left[\mathrm{TiF}_{6}\right]^{2-}+2 \mathrm{H}_{2} \mathrm{O} \\
\mathrm{TiO}_{2}+\left[\mathrm{H}_{2} \mathrm{EDTA}\right]^{2-}+\mathrm{H}^{+} \longrightarrow[\mathrm{TiO}(\mathrm{HEDTA})]^{-}+\mathrm{H}_{2} \mathrm{O} \\
\mathrm{TiO}_{2}+\left[\mathrm{H}_{2} \mathrm{EDTA}\right]^{2-}+2 \mathrm{H}^{+} \longrightarrow[\mathrm{Ti}(\mathrm{EDTA})]+2 \mathrm{H}_{2} \mathrm{O}
\end{gathered}
$$

Therefore, oxide layer becomes thinner with time at a faster rate.

As mentioned earlier, there are three processes control the formation of TNT, namely, field-assisted oxidation of $\mathrm{Ti}$, field-assisted dissolution of Ti metal ions, and chemical dissolution of $\mathrm{TiO}_{2}$. As thickness reduces, field-assisted dissolution will reoccur and pore will penetrate inside Ti and tubes become longer [40]. Therefore, substantial dissolution in the presence of EDTA could enhance the growth rate of nanotubes as both the field-assisted and chemical etching occur at a faster rate. 


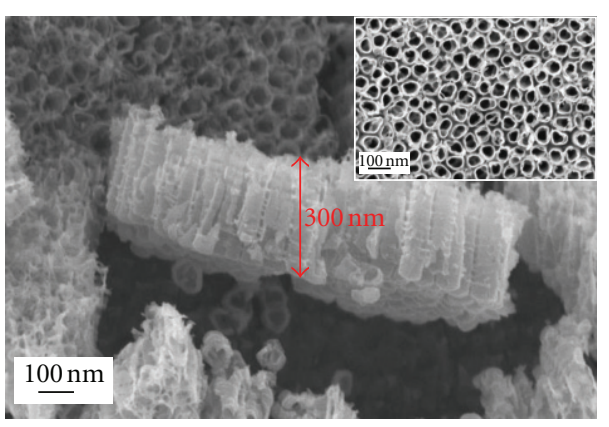

(a)

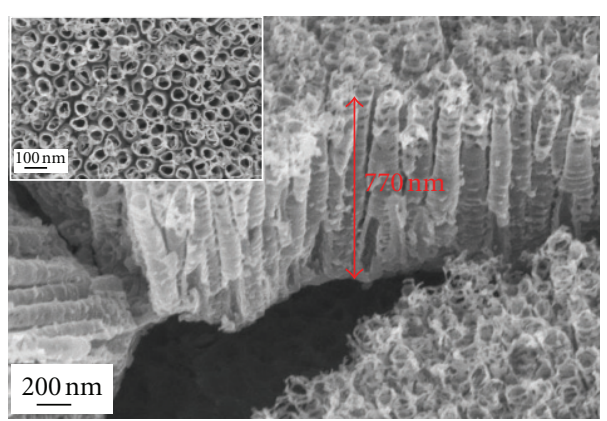

(b)

FIGURE 5: FESEM cross-sectional view images of (a) TNT and (b) TNT/EDTA; the insets show the top view images of the corresponding samples.

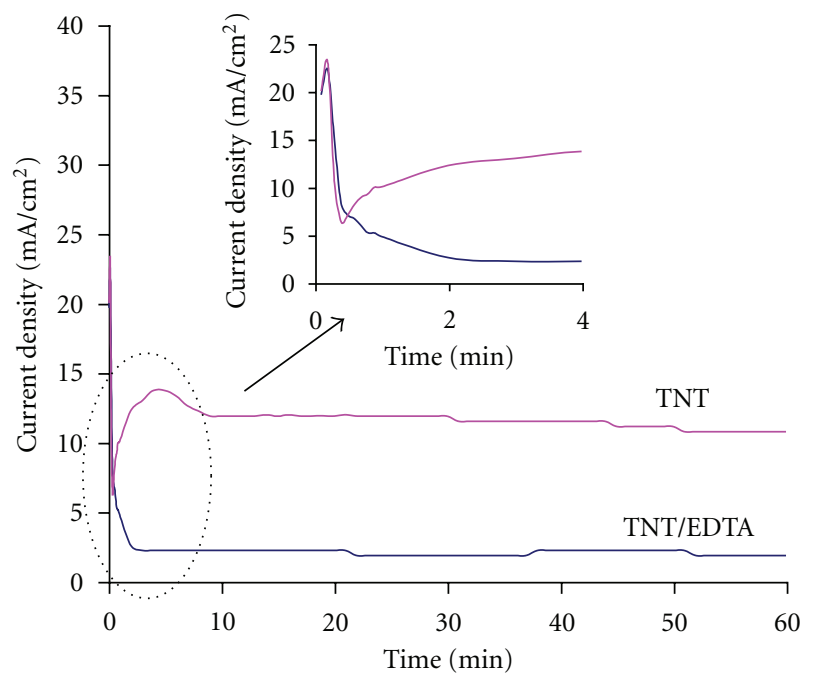

FIGURE 6: Current density transient recorded during anodization with and without the presence of complexing agent. Inset is the magnifying view of the initial anodization stage.

However, it was observed that nanotube length increases with elevating anodization duration from 30 to $60 \mathrm{~min}$ after which it drops to about $690 \pm 36 \mathrm{~nm}$ after $120 \mathrm{~min}$ of anodization. It was also found that for TNT/EDTA sample, tube diameter remained constant with increasing anodization time, indicating that anodization duration mainly influences the depth of the nanotubes. The result is in good agreement with the literature data [46].

3.4. Photoelectrochemical Response of TNT. In order to evaluate the effect of different dimensions and crystallization of TNT on its photoelectrochemical response, the as-anodized and calcined TNTs synthesized at different electrolyte temperatures, voltage ramps and presence of EDTA were used as photoanode in the photoelectrochemical cell. The photocurrent was recorded by intermittently irradiating the electrodes from halogen lamp using linear sweep photovoltammetry. Figure 7 illustrates the corresponding experimental results of as-anodized and calcined TNTs prepared at various bath temperatures and voltage ramps.
Apparently, all the as-anodized TNTs show a negligible photocurrent density (as low as $2 \mu \mathrm{A} / \mathrm{cm}^{2}$ ) and substantial enhancement of photoresponse after calcination at $500^{\circ} \mathrm{C}$. This result is expected as the as-anodized TNT exhibited amorphous structure as revealed by the XRD study (Figures 1(a) and 4(a)). Usually, amorphous TNT contains more defect sites than the crystallized one, which causes the recombination of photogenerated charge carriers. Therefore, photogenerated electrons have difficulty to conduct charge transfer on amorphous TNT under external bias condition to generate photocurrent [7]. This kind of TNT photoanode will be expected to exhibit very low photocatalytic or photoelectrocatalytic reactivity. On the contrary, significant increases in photocurrent for calcined samples is likely attributed to the higher photogenerated electron-hole pairs caused by the higher amount of anatase and rutile content. This result also indicates the necessity to form crystalline phase for the application of this material as photoanode.

For calcined TNT prepared at various bath temperatures, photoresponse increases with decreasing bath temperature except for TNT fabricated at $10^{\circ} \mathrm{C}$. Higher photocurrent means that photogenerated electrons have been transferred from TNT photoanode to counter electrode more effectively via external circuit under illumination. Interestingly, it is found that even though TNT length produced at room temperature, about $27^{\circ} \mathrm{C}$ (tube length $\sim 290 \mathrm{~nm}$ ), is relatively shorter, the photocurrent response is yet comparable to that synthesized at $10^{\circ} \mathrm{C}$ (tube length $\sim 430 \mathrm{~nm}$ ). Two reasons may account for such observation. Firstly, as shown in Figure 2(a), debris covering the surface of nanotubes could be observed for TNT synthesized at $10^{\circ} \mathrm{C}$. This unwanted debris will reduce the surface area and thus limit the light absorption ability of the sample. Therefore, for TNT synthesized at $27^{\circ} \mathrm{C}$, its photoresponse is still comparable even though it has a relatively shorter tube length. Secondly, wall thickness and tube diameters are critical in influencing the photoresponse. In this respect, TNT with thinner wall $(15 \mathrm{~nm})$ in our study demonstrated relatively higher photocurrent response than that of thicker wall $(21 \mathrm{~nm})$. It is known that when $\mathrm{TiO}_{2}$ is irradiated, electrons and holes are generated. Unless they could be separated by either being trapped or migrateing to the semiconductor surface, otherwise they always recombine immediately once photogenerated [30,47]. With thinner 


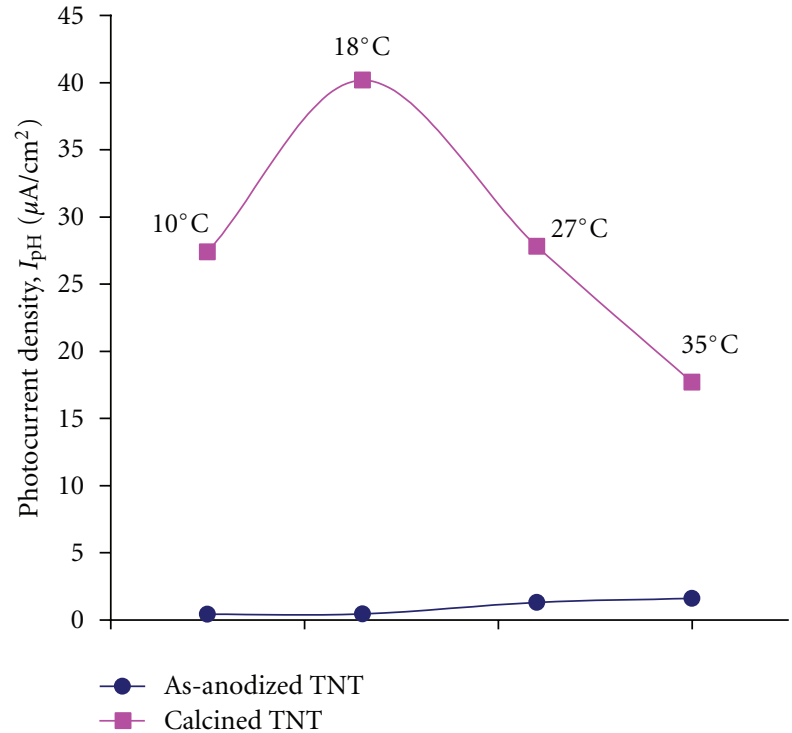

(a)

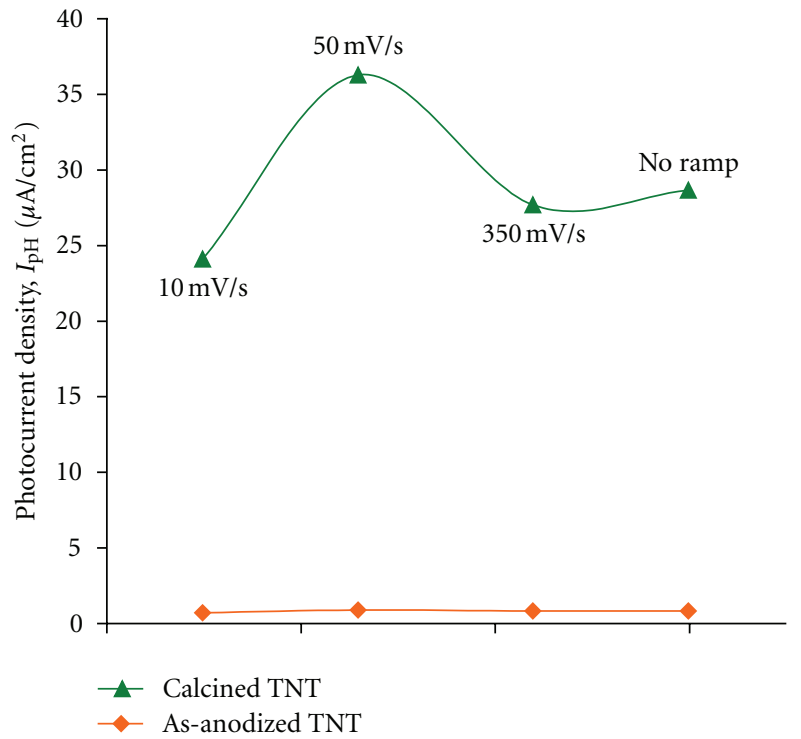

(b)

Figure 7: Comparison of photocurrent density at $1.0 \mathrm{~V}$ (versus $\mathrm{Ag} / \mathrm{AgCl}$ ) of as-anodized and calcined TNTs prepared in pH 4 electrolytes (a) at different electrolyte temperatures and (b) using different voltage ramps prior to constant voltage of $20 \mathrm{~V}$. All the photocurrent measurements were obtained using $10 \mathrm{ppm}$ methyl orange solution from $300 \mathrm{~W}$ halogen lamp at scan rate of $20 \mathrm{mV} / \mathrm{s}$.

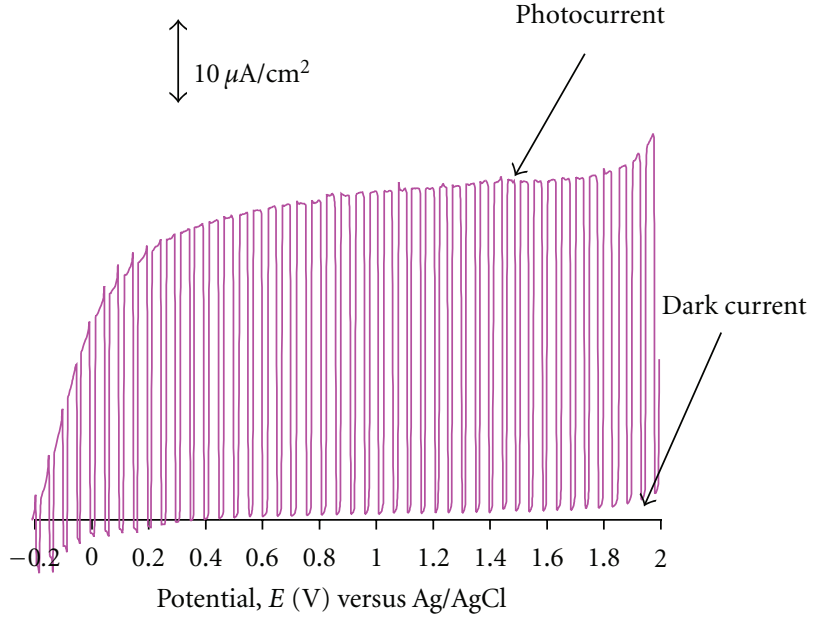

(a)

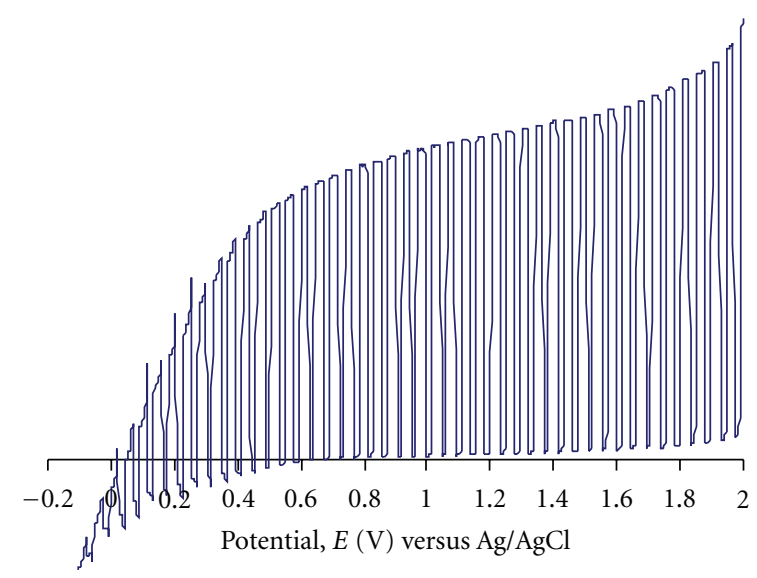

(b)

Figure 8: Photoresponse of (a) TNT/EDTA and (b) TNT prepared at $20 \mathrm{~V}$ for $1 \mathrm{~h}$ at $\mathrm{pH}$ 4.5. All the photocurrent measurement were obtained using $10 \mathrm{ppm}$ methyl orange with $0.1 \mathrm{M} \mathrm{KCl}$ as supporting electrolyte from $300 \mathrm{~W}$ halogen lamp at scan rate of $20 \mathrm{mV} / \mathrm{s}$.

wall, photogenerated hole could reach the oxidizable species in the electrolyte easily and reducing the recombination. Moreover, surface states increase rapidly as the wall thickness reduced, and thus resulting in low surface recombination [48]. On the other hand, TNT synthesized at $18^{\circ} \mathrm{C}$ demonstrated the highest photocurrent density, and its value is about twice the value of that fabricated at $35^{\circ} \mathrm{C}$. Apart from short tube length obtained at $35^{\circ} \mathrm{C}$ which in return resulted in low incident photon absorption, low photoelectrochemical current density observed may reflect the quick recombination of photogenerated charge carriers and low transfer efficiency of photogenerated electron to counter electrode via external circuit.

Generally, TNT obtained with voltage ramp prior to $2 \mathrm{~h}$ constant voltage has comparable or longer nanotube length than without ramp. Longest tube was obtained by applying a voltage ramp of $50 \mathrm{mV} / \mathrm{s}$ prior to constant voltage. Considering similar tube diameter and wall thickness obtained at different voltage ramps, availability of large active surface area increases linearly with increasing tube length. Thus, higher photocurrent density for TNT synthesized at $50 \mathrm{mV} / \mathrm{s}$ voltage ramping was mostly ascribed to the higher active 
surface area which improves the light-harvesting capability and better photon absorption of this photoanode.

Figures $8(\mathrm{a})$ and $8(\mathrm{~b})$ show the variation of photocurrent density with potential for calcined TNT/EDTA and TNT prepared at $\mathrm{pH} 4.5$, respectively. Both curves exhibited the typical of n-type semiconductor. Both samples exhibited almost negligible dark current, indicating inactive photoreaction of TNT under dark condition (without illumination). However, the responsive photoresponse for both samples increased drastically under light illumination implying good transfer and recombination of photo-induced charge carriers [49]. In comparison, TNT/EDTA sample exhibited higher photocurrent than TNT sample due to longer tubes obtained than the latter. Moreover, enhancement of photocurrent density could be observed over entire potential range of +1.5 to $-0.2 \mathrm{~V}$, implying higher photoelectrochemical reactivity of TNT/EDTA photoanode. The curve slope is also steeper for TNT/EDTA in comparison to that of TNT. Therefore, one could expect that TNT fabricated with the addition of EDTA may demonstrate high photoresponse and act as promising material as photoanode in photoelectrochemical cells.

\section{Conclusions}

In summary, we have successfully synthesized self-organized TNT using electrochemical method in $\mathrm{NH}_{4} \mathrm{~F}$ containing electrolyte. The influence of electrolyte temperature, voltage ramp prior to constant voltage, and the addition of EDTA on the dimensions of TNT has been investigated. It was found that TNT can still be fabricated at $35^{\circ} \mathrm{C}$; however, the tube length decreases whereas tube diameter increases with elevated temperature from 10 to $35^{\circ} \mathrm{C}$. On the other hand, applying voltage ramp prior to constant voltage at $20 \mathrm{~V}$ during anodization has no influence on the tube diameter and wall thickness. Nevertheless, optimized voltage ramp at $50 \mathrm{mV} / \mathrm{s}$ resulted in thickest oxide layers. In addition, nanotube growth rate can be enhanced dramatically with the addition of EDTA. Based on the photoelectrochemical measurement, it can be concluded that structure of TNT including tube length and wall thickness is important factor influencing the photoresponse. Therefore, electrochemical parameters can be manipulated to obtain desired dimensions for various applications such as solar cells and photoelectrocatalysis.

\section{Acknowledgment}

This work was supported by an FRGS grant (no. 01-04-10859FR) from the Ministry of Higher Education, Malaysia.

\section{References}

[1] M. R. Hoffmann, S. T. Martin, W. Choi, and D. W. Bahnemann, "Environmental applications of semiconductor photocatalysis," Chemical Reviews, vol. 95, no. 1, pp. 69-96, 1995.

[2] J. Yu, L. Zhang, B. Cheng, and Y. Su, "Hydrothermal preparation and photocatalytic activity of hierarchically sponge-like macro-/mesoporous Titania," Journal of Physical Chemistry C, vol. 111, no. 28, pp. 10582-10589, 2007.
[3] F. Han, V. S. R. Kambala, M. Srinivasan, D. Rajarathnam, and R. Naidu, "Tailored titanium dioxide photocatalysts for the degradation of organic dyes in wastewater treatment: a review," Applied Catalysis A: General, vol. 359, no. 1-2, pp. 2540, 2009.

[4] J. A. Byrne, P. A. Fernandez-Ibañez, P. S.M. Dunlop, D. M.A. Alrousan, and J. W.J. Hamilton, "Photocatalytic enhancement for solar disinfection of water: a review," International Journal of Photoenergy, vol. 2011, Article ID 798051, 2011.

[5] J. Yu, W. Wang, B. Cheng, and B. L. Su, "Enhancement of photocatalytic activity of Mesporous $\mathrm{TiO}_{2}$ powders by hydrothermal surface fluorination treatment," Journal of Physical Chemistry C, vol. 113, no. 16, pp. 6743-6750, 2009.

[6] H. J. Oh, J. H. Lee, Y. J. Kim, S. J. Suh, J. H. Lee, and C. S. Chi, "Synthesis of effective titania nanotubes for wastewater purification," Applied Catalysis B: Environmental, vol. 84, no. 1-2, pp. 142-147, 2008.

[7] J. Yu, G. Dai, and B. Cheng, "Effect of crystallization methods on morphology and photocatalytic activity of anodized $\mathrm{TiO}_{2}$ nanotube array films," Journal of Physical Chemistry C, vol. 114, no. 45, pp. 19378-19385, 2010.

[8] G. Dai, J. Yu, and G. Liu, "Synthesis and enhanced visiblelight photoelectrocatalytic activity of $\mathrm{p}-\mathrm{N}$ junction $\mathrm{BiOI} / \mathrm{TiO}_{2}$ nanotube arrays," Journal of Physical Chemistry C, vol. 115, no. 15, pp. 7339-7346, 2011.

[9] S. Wang, L. Zhao, J. Ran, Z. Shu, G. Dai, and P. Zhai, "Effects of calcination temperatures on photocatalytic activity of ordered titanate nanoribbon $/ \mathrm{SnO}_{2}$ films fabricated during an EPD process," International Journal of Photoenergy, vol. 2012, Article ID 472958, 2012.

[10] N. K. Allam, K. Shankar, and C. A. Grimes, "Photoelectrochemical and water photoelectrolysis properties of ordered $\mathrm{TiO}_{2}$ nanotubes fabricated by $\mathrm{Ti}$ anodization in fluoride-free $\mathrm{HCl}$ electrolytes," Journal of Materials Chemistry, vol. 18, no. 20, pp. 2341-2348, 2008.

[11] K. Shankar, J. I. Basham, N. K. Allam et al., "Recent advances In the use of $\mathrm{TiO}_{2}$ nanotube and nanowire arrays for oxidative photoelectrochemistry," Journal of Physical Chemistry C, vol. 113, no. 16, pp. 6327-6359, 2009.

[12] G. K. Mor, M. A. Carvalho, O. K. Varghese, M. V. Pishko, and C. A. Grimes, "A room-temperature $\mathrm{TiO}_{2}$-nanotube hydrogen sensor able to self-clean photoactively from environmental contamination," Journal of Materials Research, vol. 19, no. 2, pp. 628-634, 2004.

[13] S. Liu and A. Chen, "Coadsorption of horseradish peroxidase with thionine on $\mathrm{TiO}_{2}$ nanotubes for biosensing," Langmuir, vol. 21, no. 18, pp. 8409-8413, 2005.

[14] Z. Xu and J. Yu, "A novel solid-state electrochemiluminescence sensor based on $\mathrm{Ru}(\mathrm{bpy})_{3}^{2+}$ immobilization on $\mathrm{TiO}_{2}$ nanotube arrays and its application for detection of amines in water," Nanotechnology, vol. 21, no. 24, Article ID 245501, 2010.

[15] J. R. Jennings, A. Ghicov, L. M. Peter, P. Schmuki, and A. B. Walker, "Dye-sensitized solar cells based on oriented $\mathrm{TiO}_{2}$ nanotube arrays: transport, trapping, and transfer of electrons," Journal of the American Chemical Society, vol. 130, no. 40, pp. 13364-13372, 2008.

[16] J. Yu, J. Fan, and K. Lv, "Anatase $\mathrm{TiO}_{2}$ nanosheets with exposed (001) facets: improved photoelectric conversion efficiency in dye-sensitized solar cells," Nanoscale, vol. 2, no. 10, pp. 21442149, 2010.

[17] A. Kar, K. S. Raja, and M. Misra, "Electrodeposition of hydroxyapatite onto nanotubular $\mathrm{TiO}_{2}$ for implant applications," Surface and Coatings Technology, vol. 201, no. 6, pp. 37233731, 2006. 
[18] K. C. Popat, L. Leoni, C. A. Grimes, and T. A. Desai, "Influence of engineered titania nanotubular surfaces on bone cells," Biomaterials, vol. 28, no. 21, pp. 3188-3197, 2007.

[19] Z. Miao, D. Xu, J. Ouyang, G. Guo, X. Zhao, and Y. Tang, "Electrochemically induced sol-gel preparation of single-crystalline $\mathrm{TiO}_{2}$ nanowires," Nano Letters, vol. 2, no. 7, pp. 717720, 2002.

[20] S.-J. Kim, N.-H. Lee, H.-J. Oh, S.-C. Jung, W.-J. Lee, and D.-H. Kim, "Photocatalytic properties of nanotubular-shaped $\mathrm{TiO}_{2}$ powders with anatase phase obtained from titanate nanotube powder through various thermal treatments," International Journal of Photoenergy, vol. 2011, Article ID 327821, 2011.

[21] T. Kasuga, M. Hiramatsu, A. Hoson, T. Sekino, and K. Niihara, "Formation of titanium oxide nanotube," Langmuir, vol. 14, no. 12, pp. 3160-3163, 1998.

[22] M. S. Sander, M. J. Côté, W. Gu, B. M. Kile, and C. P. Tripp, "Template-assisted fabrication of dense, aligned arrays of titania nanotubes with well-controlled dimensions on substrates," Advanced Materials, vol. 16, no. 22, pp. 2052-2057, 2004.

[23] Z. R. Tian, J. A. Voigt, J. Liu, B. McKenzie, and H. Xu, "Large oriented arrays and continuous films of $\mathrm{TiO}_{2}$-based nanotubes," Journal of the American Chemical Society, vol. 125, no. 41, pp. 12384-12385, 2003.

[24] J. M. Macak, H. Tsuchiya, A. Ghicov et al., " $\mathrm{TiO}_{2}$ nanotubes: self-organized electrochemical formation, properties and applications," Current Opinion in Solid State and Materials Science, vol. 11, no. 1-2, pp. 3-18, 2007.

[25] V. Zwilling, E. Darque-Ceretti, A. Boutry-Forveille, D. David, M. Y. Perrin, and M. Aucouturier, "Structure and physicochemistry of anodic oxide films on titanium and TA6V alloy," Surface and Interface Analysis, vol. 27, no. 7, pp. 629-637, 1999.

[26] C. A. Grimes, D. Gong, O. K. Varghese et al., "Titanium oxide nanotube arrays prepared by anodic oxidation," Journal of Materials Research, vol. 16, no. 12, pp. 3331-3334, 2001.

[27] M. Zhou, J. Yu, B. Cheng, and H. Yu, "Preparation and photocatalytic activity of Fe-doped mesoporous titanium dioxide nanocrystalline photocatalysts," Materials Chemistry and Physics, vol. 93, no. 1, pp. 159-163, 2005.

[28] J. Yu, G. Dai, and B. Huang, "Fabrication and characterization of visible-light-driven plasmonic photocatalyst $\mathrm{Ag} / \mathrm{AgCl} / \mathrm{TiO}_{2}$ nanotube arrays," Journal of Physical Chemistry C, vol. 113, no. 37, pp. 16394-16401, 2009.

[29] Z. Xu and J. Yu, "Visible-light-induced photoelectrochemical behaviors of Fe-modified $\mathrm{TiO}_{2}$ nanotube arrays," Nanoscale, vol. 3, no. 8, pp. 3138-3144, 2011.

[30] J. Yu and B. Wang, "Effect of calcination temperature on morphology and photoelectrochemical properties of anodized titanium dioxide nanotube arrays," Applied Catalysis B: Environmental, vol. 94, no. 3-4, pp. 295-302, 2010.

[31] J. M. Macak and P. Schmuki, "Anodic growth of self-organized anodic $\mathrm{TiO}_{2}$ nanotubes in viscous electrolytes," Electrochimica Acta, vol. 52, no. 3, pp. 1258-1264, 2006.

[32] S. Yoriya and C. A. Grimes, "Self-Assembled $\mathrm{TiO}_{2}$ nanotube arrays by anodization of titanium in diethylene glycol: approach to extended pore widening," Langmuir, vol. 26, no. 1, pp. 417-420, 2010.

[33] K. Zhu, N. R. Neale, A. Miedaner, and A. J. Frank, "Enhanced charge-collection efficiencies and light scattering in dye-sensitized solar cells using oriented $\mathrm{TiO}_{2}$ nanotubes arrays," Nano Letters, vol. 7, no. 1, pp. 69-74, 2007.

[34] J. M. Macak, H. Hildebrand, U. Marten-Jahns, and P. Schmuki, "Mechanistic aspects and growth of large diameter self-orga- nized $\mathrm{TiO}_{2}$ nanotubes," Journal of Electroanalytical Chemistry, vol. 621, no. 2, pp. 254-266, 2008.

[35] V. M. Prida, E. Manova, V. Vega et al., “Temperature influence on the anodic growth of self-aligned Titanium dioxide nanotube arrays," Journal of Magnetism and Magnetic Materials, vol. 316, no. 2, pp. 110-113, 2007.

[36] L. Y. Chin, Z. Zainal, M. Z. Hussein, and T. W. Tee, "Fabrication of highly ordered $\mathrm{TiO}_{2}$ nanotubes from fluoride containing aqueous electrolyte by anodic oxidation and their photoelectrochemical response," Journal of Nanoscience and Nanotechnology, vol. 11, no. 6, pp. 4900-4909, 2011.

[37] S. Banerjee, M. Misra, S. K. Mohapatra, C. Howard, S. K. Mohapatra, and S. K. Kamilla, "Formation of chelating agent driven anodized $\mathrm{TiO}_{2}$ nanotubular membrane and its photovoltaic application," Nanotechnology, vol. 21, no. 14, Article ID 145201, pp. 1-9, 2010.

[38] X. Xiao, K. Ouyang, R. Liu, and J. Liang, "Anatase type titania nanotube arrays direct fabricated by anodization without annealing," Applied Surface Science, vol. 255, no. 6, pp. 36593663, 2009.

[39] G. K. Mor, K. Shankar, M. Paulose, O. K. Varghese, and C. A. Grimes, "Enhanced photocleavage of water using titania nanotube arrays," Nano Letters, vol. 5, no. 1, pp. 191-195, 2005.

[40] Z. Lockman, S. Sreekantan, S. Ismail, L. Schmidt-Mende, and J. L. MacManus-Driscoll, "Influence of anodisation voltage on the dimension of titania nanotubes," Journal of Alloys and Compounds, vol. 503, no. 2, pp. 359-364, 2010.

[41] Y. Lai, H. Zhuang, L. Sun, Z. Chen, and C. Lin, "Self-organized $\mathrm{TiO}_{2}$ nanotubes in mixed organic-inorganic electrolytes and their photoelectrochemical performance," Electrochimica Acta, vol. 54, no. 26, pp. 6536-6542, 2009.

[42] H. Yin, H. Liu, and W. Z. Shen, "The large diameter and fast growth of self-organized $\mathrm{TiO}_{2}$ nanotube arrays achieved via electrochemical anodization," Nanotechnology, vol. 21, no. 3, Article ID 035601, 2010.

[43] J. M. Macák, H. Tsuchiya, and P. Schmuki, "High-aspectratio $\mathrm{TiO}_{2}$ nanotubes by anodization of titanium," Angewandte Chemie-International Edition, vol. 44, no. 14, pp. 2100-2102, 2005.

[44] M. Paulose, K. Shankar, S. Yoriya et al., "Anodic growth of highly ordered $\mathrm{TiO}_{2}$ nanotube arrays to $134 \mu \mathrm{m}$ in length," Journal of Physical Chemistry B, vol. 110, no. 33, pp. 1617916184, 2006.

[45] B. Karadakov and P. Nenova, "Spectrophotometric study of the reaction of titanium(IV) and ethylenediaminetetraacetic acid (EDTA)," Journal of Inorganic and Nuclear Chemistry, vol. 33, no. 8, pp. 2541-2545, 1971.

[46] E. Y. Kim, J. H. Park, and G. Y. Han, "Design of $\mathrm{TiO}_{2}$ nanotube array-based water-splitting reactor for hydrogen generation," Journal of Power Sources, vol. 184, no. 1, pp. 284-287, 2008.

[47] A. Hagfeldt, H. Lindström, S. Södergren, and S. E. Lindquist, "Photoelectrochemical studies of colloidal $\mathrm{TiO}_{2}$ films: the effect of oxygen studied by photocurrent transients," Journal of Electroanalytical Chemistry, vol. 381, no. 1-2, pp. 39-46, 1995.

[48] H. C. Liang and X. Z. Li, "Effects of structure of anodic $\mathrm{TiO}_{2}$ nanotube arrays on photocatalytic activity for the degradation of 2,3-dichlorophenol in aqueous solution," Journal of Hazardous Materials, vol. 162, no. 2-3, pp. 1415-1422, 2009.

[49] Y. Xie, L. M. Zhou, and H. Huang, "Enhanced photoelectrochemical current response of titania nanotube array," Materials Letters, vol. 60, no. 29-30, pp. 3558-3560, 2006. 


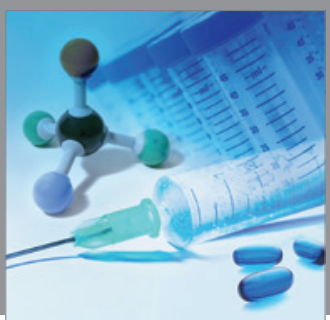

International Journal of

Medicinal Chemistry

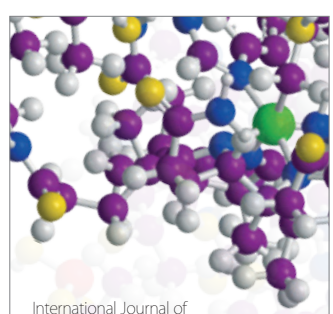

Carbohydrate Chemistry

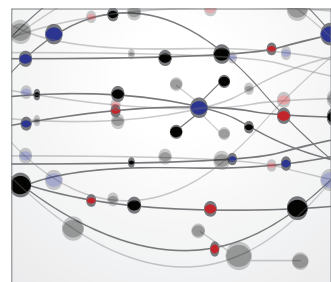

The Scientific World Journal
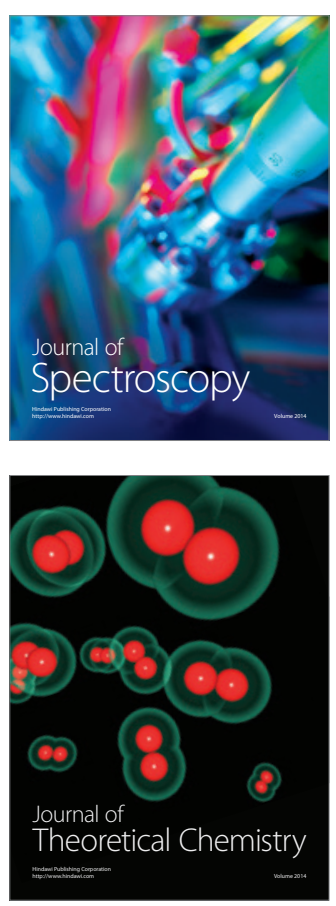
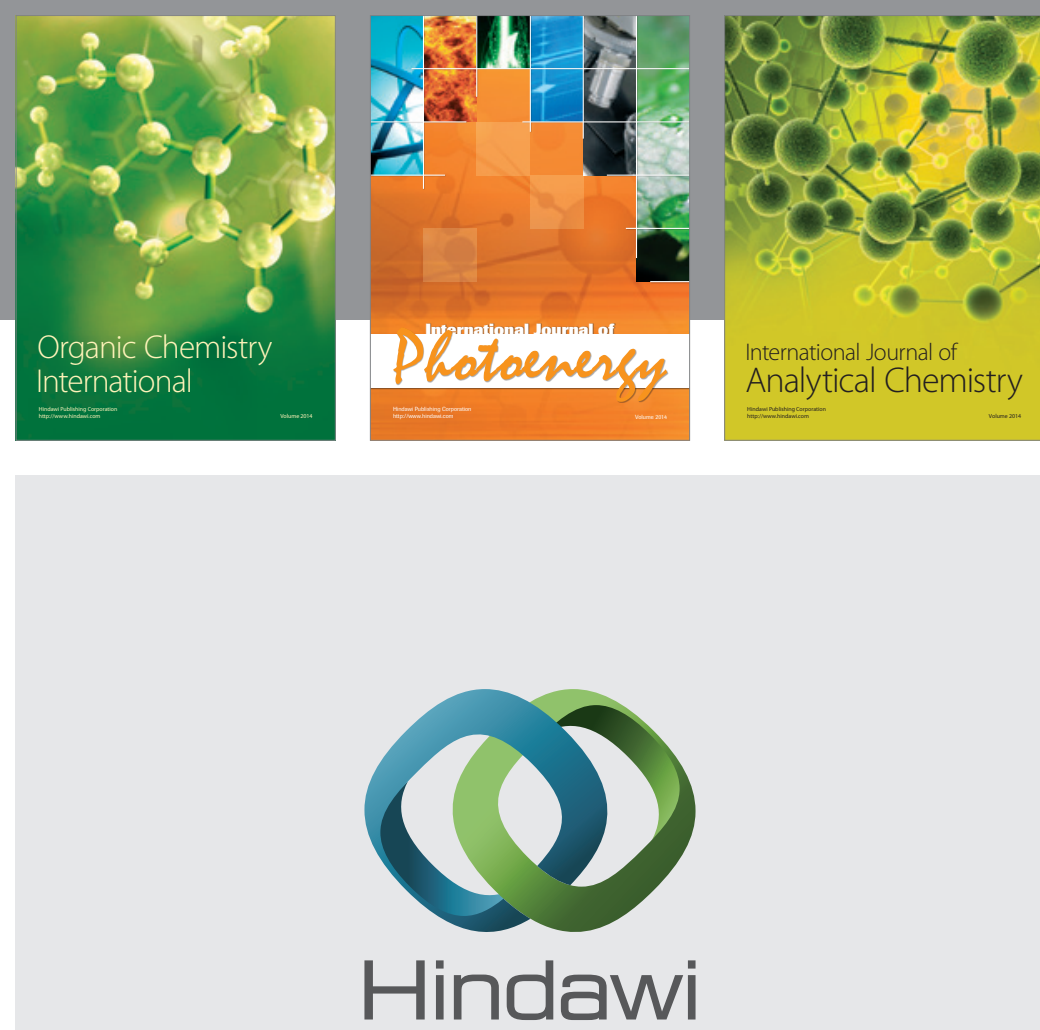

Submit your manuscripts at

http://www.hindawi.com
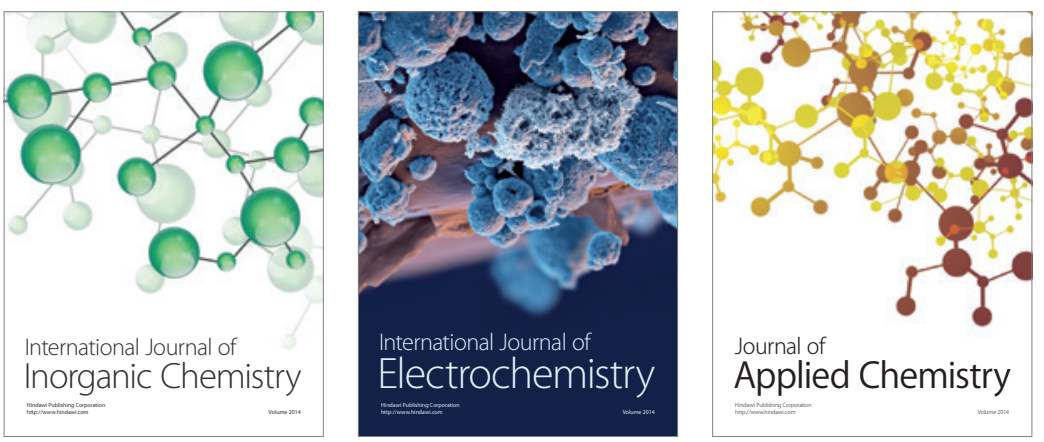

Journal of

Applied Chemistry
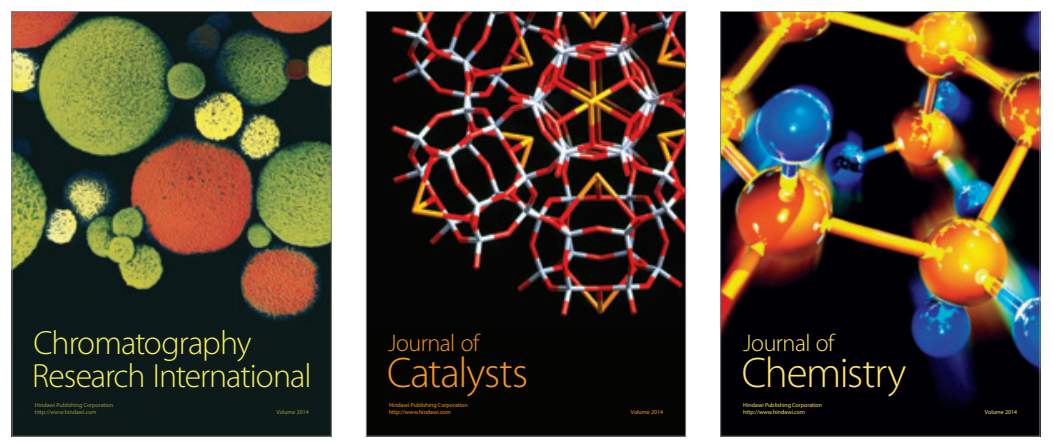
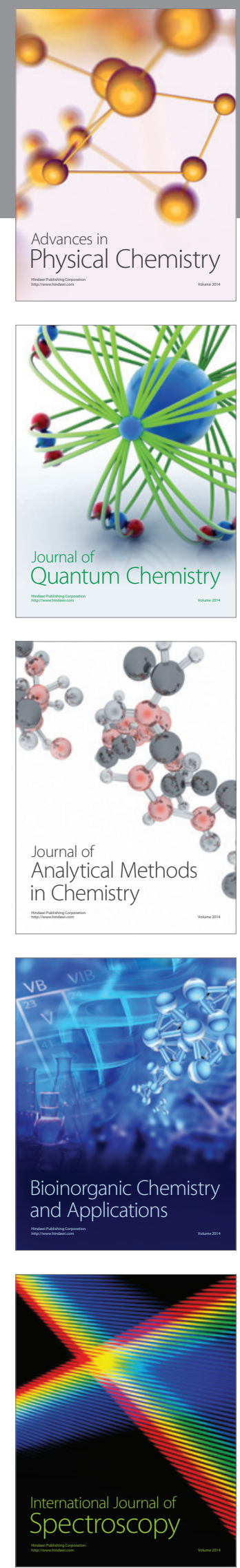